\title{
Towards Recycling Cost Modelling Framework for Carbon Fibre Composites
}

\author{
Essam SHEHAB ${ }^{\mathrm{a}, \mathrm{b}, 1}$, Ghunaim ALANAZI ${ }^{\mathrm{a}}$ and Shoaib SARFRAZ ${ }^{\mathrm{a}}$ \\ ${ }^{a}$ Manufacturing Department, Cranfield University, Cranfield, Bedford, MK43 OAL, UK \\ ${ }^{\mathrm{b}}$ School of Engineering, Nazarbayev University, Astana, Kazakhstan
}

\begin{abstract}
Environmental legislation puts more pressure on solving carbon fibre composites (CFC) waste management through recycling and reuse. Despite their superior properties, CFC creates environmental issue when it reaches its end of life. The aim of this paper is to to provide a framework that represents the first step towards the development of a cost modelling framework for recycling CFC materials. The focus is the mechanical and thermal (Pyrolysis) recycling process. The activities and the tasks related to each recycling process are presented. The research has been accomplished by embracing a qualitative research plan consisting of five phases. To enhance understanding of the parameters affecting the cost of the recycling process, the major and detailed cost drivers are recognised. The developed costing framework has been implemented in an IT-based cost estimation tool for easy handling and calculation of the cost parameters. This tool identifies all tasks and activities related to the two recycling processes.
\end{abstract}

Keywords. Mechanical and Thermal Recycling, Cost Modelling, Carbon Fibre Composites

\section{Introduction}

There is a significant focus by industries on composites materials used in many applications in various sectors such as automotive, aerospace and construction. Due to their high strength, lightweight, stiffness, fatigue and other mechanical properties, composites are used instead of many conventional materials such as metals and alloys. Carbon Fibre Composites (CFC) are extensively used in aerospace, automotive and marine sectors. CFC are made up of a polymer matrix reinforced with carbon fibers. There are two types of CFC depending on their polymer material: thermoset and thermoplastic. Thermoset composites use thermosetting (cross inked) polymers such as epoxy, vinylester, polyester and phenolics, and once cured, a thermoset part cannot be changed or remelted. Thermoplastic polymers, in contrast, can be melted, reshaped and reformed. The most common polymers used in the thermoplastic composite are polyether ether ketone, polyphenylene sulphide, polysulfone and polyimides. The current research focuses on the recycling of thermoset CFC due to its high cost compared with other composites materials [1].

The CFC community is aware of the increasing appeal of the green agenda and the legislation that enforces it. Environmental legislation aims to force the CFC manufacturers to reconsider the end of life options and reduce the amount of composites

\footnotetext{
${ }^{1}$ Corresponding Author, Email: e.shehab@cranfield.ac.uk.
} 
sent to landfill. Therefore, estimating the cost of the available CFC composites recycling methods either for end of life or manufacturing waste is an essential need. This estimation process, in addition, will reveal the cost in each stage and spotlight further improvements to be done.

\section{Literature Review}

The global business and manufacturing environment is becoming even more competitive than before, and cost is a key factor for success in this market. Knowing the cost associated with the $\mathrm{CFC}$ recycling process is essential for determining success or failure. It is crucial for companies to have a tool that gives them a clear idea about the cost associated with the recycling process.

CFC have received attention from several industries in the last few decades. Many companies increasingly use carbon composites in their products, for example, Airbus, Boeing, Formula 1 car racing and windmill companies [2]. According to Warrior [3], the current annual worldwide carbon fibre consumption is approximately 30,000 tonnes. The main markets are aerospace and automotive.

The high stiffness, strength and low density of CFC led them to be preferred by many manufacturers for the reason of reducing emissions and fuel consumption. Composites are widely used in applications in which high performance with lightweight are needed. Unlike traditional materials, composites offer numerous advantages. They have improved stiffness compared with other materials like steel and aluminium. High fatigue strength along with corrosion resistance is also higher than in other materials. Composite materials provide $20 \%$ strength-to-weight ratio, which is better than for many metals. A further advantage of composite materials is that they can be shaped into complex forms easier than metallic materials. This significant advantage reduces the number of parts in a given component. This has an effect on the fabrication time required for the parts [4-6]. However, composites also have some drawbacks which are: (i) higher material cost; (ii) long development time; (iii) dependence of temperature resistance on matrix material; and (iv) difficulties in recycling [5,7].

Composite recycling is increasingly important owing to the rapidly increasing use of these materials in many sectors such as aerospace, automotive and energy. Typical examples of the extensive applications of CFC are in both Airbus and Boeing civil aircraft families such as A350 XWB (52\% of total mass CFC), A380 (25\% CFC) and B787 (50\% CFC).

The land-filling of manufacturing waste or end of life composites is no longer a commercially viable option as various European directives (e.g. Council Directive, 1999/31/EC) are forcing manufacturers and suppliers to accept responsibility for recycling end of life wastes [8]. It is already illegal to landfill composites waste in many EU countries. Furthermore, political and environmental pressures will force manufacturers to consider recycling composite materials more in the coming years [9].

Proven technologies for recycling thermoset composite materials can be classified as mechanical, thermal and chemical recycling $[10,11]$. Mechanical recycling techniques involve the use of grinding techniques of all of the constituents of the original composite to comminute the scrap material and produce recyclate products in different size ranges suitable for reuse as fillers or partial reinforcement in new composite material $[10,12]$. Thermal processes are used to break the scrap down into materials and energy. Fluidised bed process has been used to recover high grade glass and carbon fibre reinforcement 
from scrap glass and carbon fibre reinforced composites [13,14]. The thermal recycling processes have the ability to tolerate more contaminated scrap materials. Recycling stages of composites and any material from end-of-life components include dealing with contamination, collecting, identifying, sorting and separating the scrap material which involves specific costs.

It is observed that little or no effort has been found to estimate the cost of recycling carbon fibre composites. Furthermore, there is a lack of information regarding some activities involved in the recycling process. Therefore, this research aims to develop a framework that represents the first step towards the development of a cost modelling framework for recycling $\mathrm{CFC}$ materials.

\section{Research Methodology}

The research methodology was composed of five phases (Figure 1). The first phase focused on conducting a comprehensive literature review and identifying the current state-of-art of disposal and recycling methods used for carbon fibre composites. The key focus in phase 2 was the data collection. A questionnaire was developed to capture the current methods used in disposal and recycling of CFC in the companies. The companies targeted to be interviewed were the environmental companies and the recycling companies. Experts in cost estimation were also targeted. The main reason for this stage was to capture the current activities and stages used in recycling of CFC along with the cost drivers associated with this process. In the next phase, the data gathered from the literature review and interviews were analysed, with focus on the cost drivers of recycling CFC. The analysis process included comparing and evaluating gathered data from the literature review and the interviews in order to build the cost modelling framework. All the collected data, cost modelling techniques and cost drivers studied were used to shape the recycling cost modelling framework in phase 4 . Finally, the validation of the developed costing framework was done through experienced experts in the field of composite materials recycling and all the gathered data were shaped into a CFC recycling cost estimation tool.

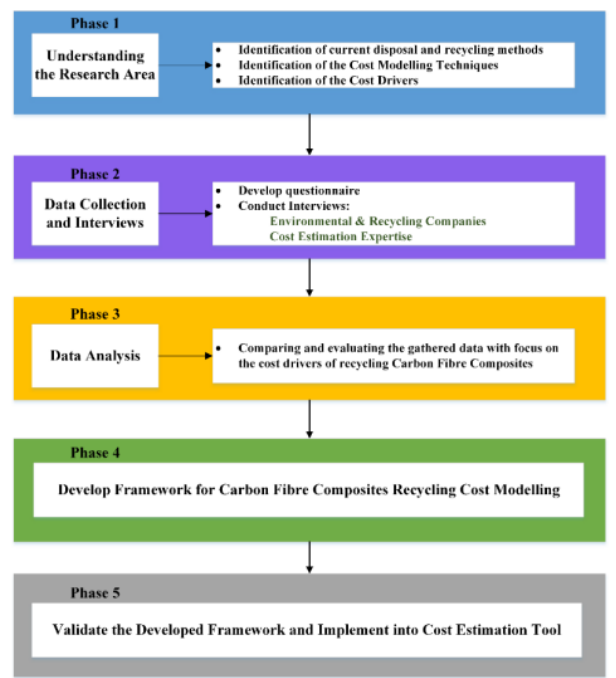

Figure 1. Research Methodology. 


\section{Development of Framework}

\subsection{Costing Framework Development Stages}

In order to perform a cost modelling for the CFC recycling, a technical cost modelling based on the recycling process description was introduced. The development of recycling CFC costing model as shown in Figure 2 was based on three phases:

- Describe the recycling process.

- Identify the work breakdown structure.

- Identify the cost drivers of the recycling process.

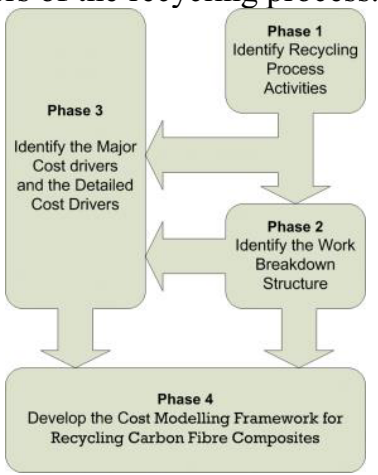

Figure 2. Costing Framework Development Stages.

\subsubsection{Recycling Process Description}

The recycling process can be divided into three steps: (i) Materials preparation collection and transportation of the materials to the recycling facility. It also includes the sorting and cleaning process; (ii) Processing - shredding and grinding CFC scrap for the mechanical recycling, and heating the CFC scrap in the thermal recycling; Packaging the finished product (fillers) is packed and ready to be shipped to the customers. Figure 3 shows the activities of mechanical and thermal (pyrolysis) process.
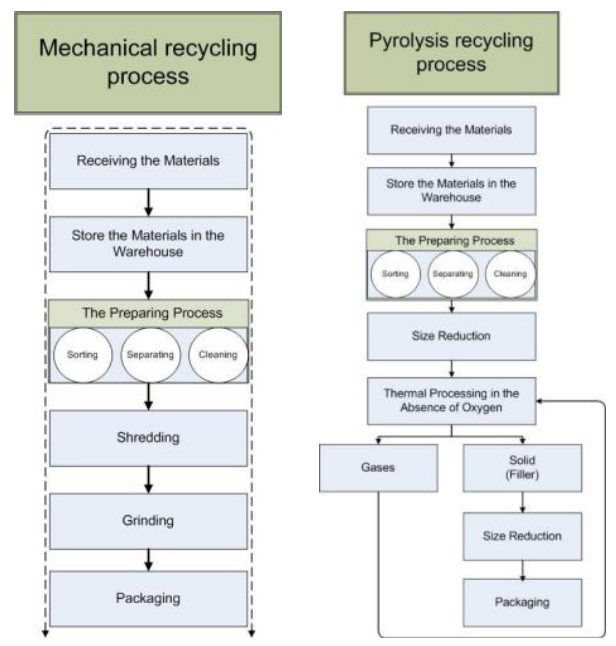

Figure 3. Mechanical and pyrolysis recycling process description. 


\subsubsection{Work Breakdown Structure (WBS)}

After identifying the activities involved in the recycling process, the work breakdown structure (WBS) was introduced. The reason behind the WBS stage is to trace all the activities, steps, machines and labours involved in the recycling process, which will in turn lead to a better understanding of the cost associated with the recycling process (the main target).

From the recycling process description, it can be seen that the top level of WBS consists of four stages. These stages are: facilities, materials, materials handling and machines. The first three stages (facilities, materials, and materials handling) were common between the mechanical and thermal recycling processes. Only the last stage for the mechanical recycling was different from the thermal recycling. A further explanation of the sublevels will be provided in the following subsections.

\subsubsection{Recycling Facilities}

In order to start the recycling service, the building spaces should be built according to the layout of the production line. Although the facilities are not part of the recycling process, it is considered as an added cost to the recycling process. The main buildings comprise of the production area and warehouse. Besides the buildings and civil works, there are main components like electrical installations, plumbing components. These components are for both the production area and the warehouse. The warehouse should be equipped with a pallet racking system and inventory control system. Furthermore, a heating, ventilating, and air conditioning (HVAC) system capable of throwing the dust out should be installed to keep the recycling area clean and dust free. Figure 4 shows the recycling facilities WBS including three subphases.

\subsubsection{Materials}

This stage is concerned with the sources of the CFC materials. As shown in Figure 5 the end of life scrap can be supplied from various sectors. The main sectors are aerospace, automotive and construction sectors. Another source of CFC materials, can be manufacturing waste, is from composites manufacturing factories and assembly plants. The last stage is related to the packaging materials such as the packing bags which are used to pack the finished product and the pallets which are used in the warehouses. The bag sizes vary from $20 \mathrm{~kg}$ to one tonne. The labours involved in this stage are the packaging labours to pack the finished product.

\subsubsection{Materials Handling}

As illustrated in Figure 6 the materials handling stage is divided into four subphases: transportation, disassembly, sorting and cleaning. The transportation phase includes the materials delivery to the recycling facility and a forklift to move the materials inside the factory. The other three activities are involved in the cleaning and sorting process. By using simple hard tools, the scrap can be disassembled into components. This step is considered an expensive step because of the high cost of manual labours, but it obtains more valuable materials. The other sorting tools are magnetic separators and an abrasive blasting (sandblasting) machine. Other activities are done manually such as removing the plastic films and the dust and preparing the solvent baths. The labours involved in the material handling stage are the forklift driver, loading labours, unloading labours, disassembly labours, separation labours and cleaning labours. 


\subsubsection{Machines}

In this stage, the mechanical recycling is different from the thermal recycling. Figure 7 and 8 show the four machines and the resources involved in mechanical and thermal recycling process respectively.

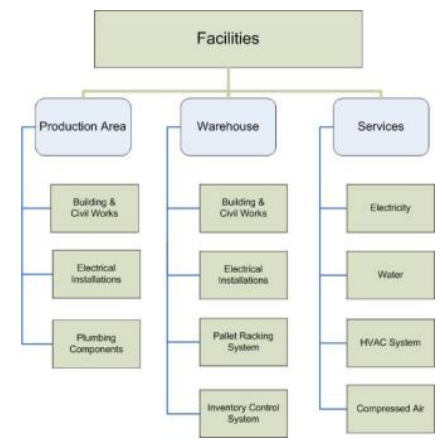

Figure 4. WBS of recycling facilities.

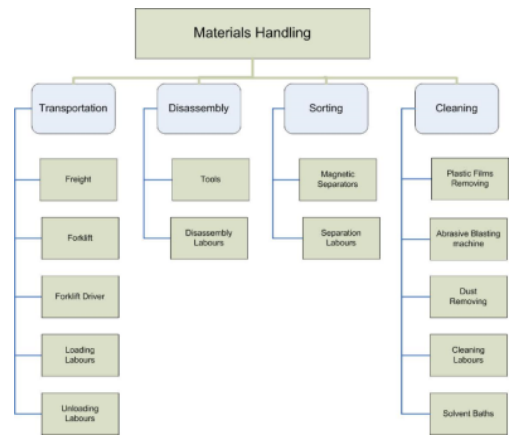

Figure 6. WBS of materials handling.

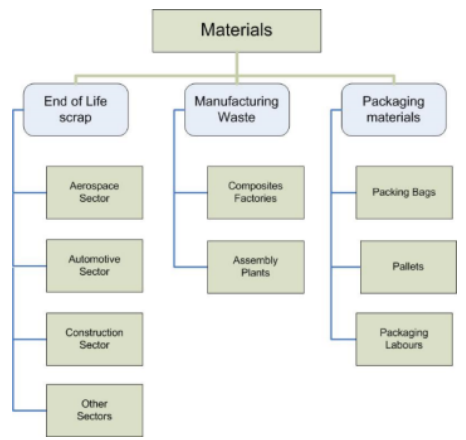

Figure 5. WBS of materials.

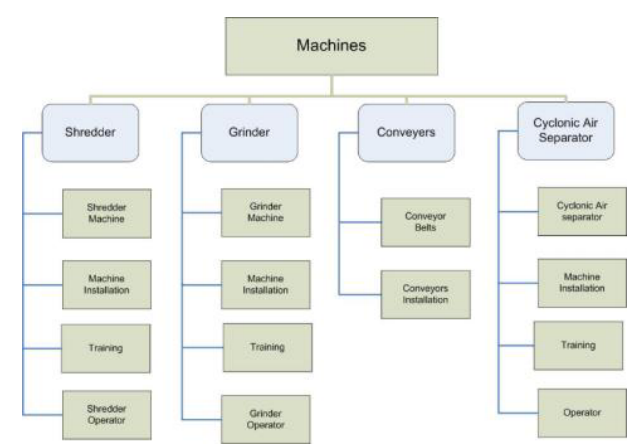

Figure 7. WBS of machines-mechanical recycling.

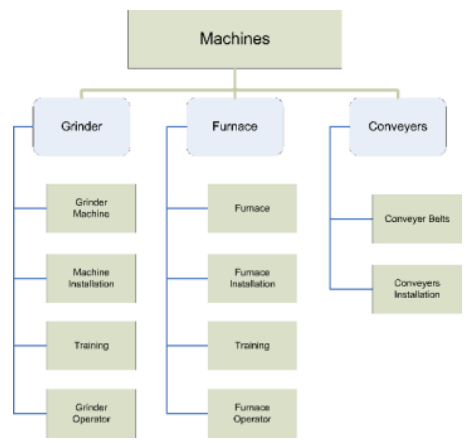

Figure 8. WBS of machines-thermal recycling.

\subsubsection{Cost Drivers}

After explaining and identifying the main activities and the WBS of the CFC recycling process, this section has decided the cost drivers that have the influence on the recycling process. The major cost drivers identified from the literature and interview analysis are machines, process time, process complexity, power requirements, labours, materials, production volume and materials identification. Since three stages of WBS are same for 
both methods as mentioned before therefore, cost drivers related to facilities, materials and materials handling can be applied for both recycling processes. The detailed cost drivers of facilities, materials and materials handling are shown in Figures 9. Whereas, Figure 10 and 11 present the machines cost drivers for mechanical and thermal recycling.

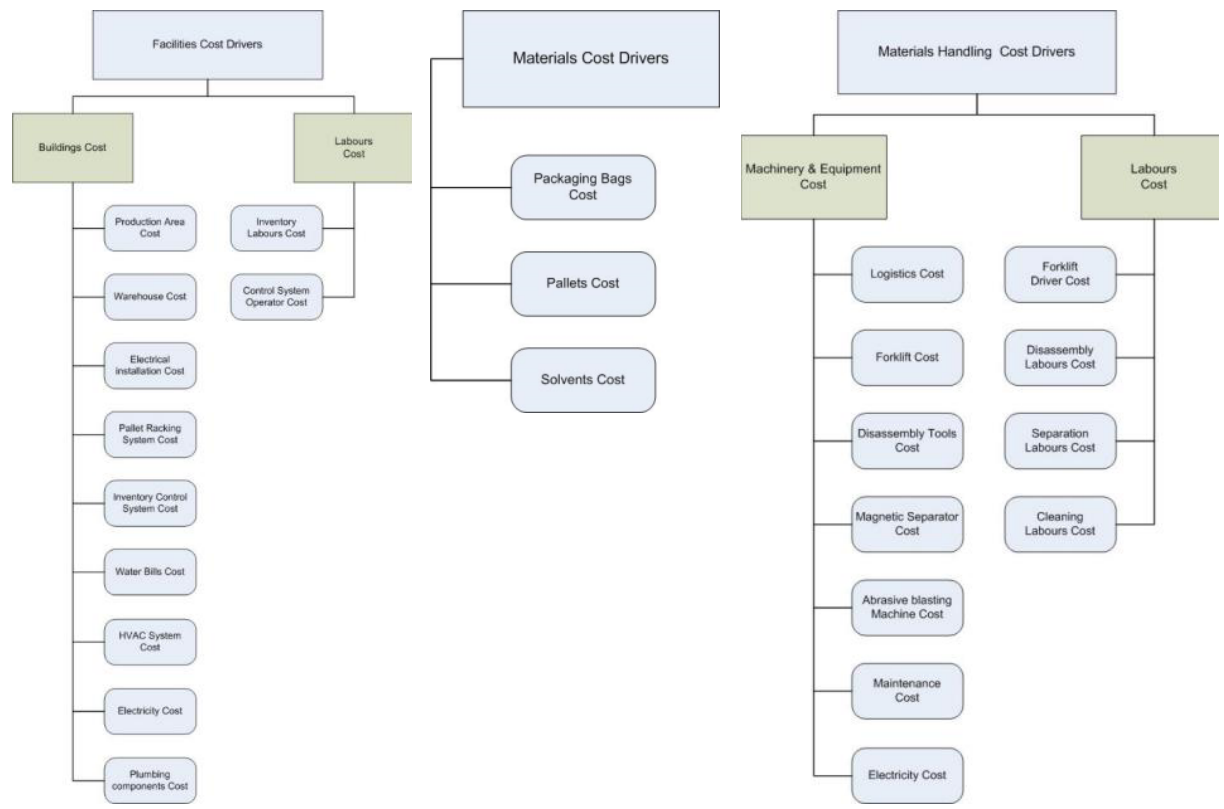

Figure 9. Detailed cost drivers of facilities, materials and materials handling.

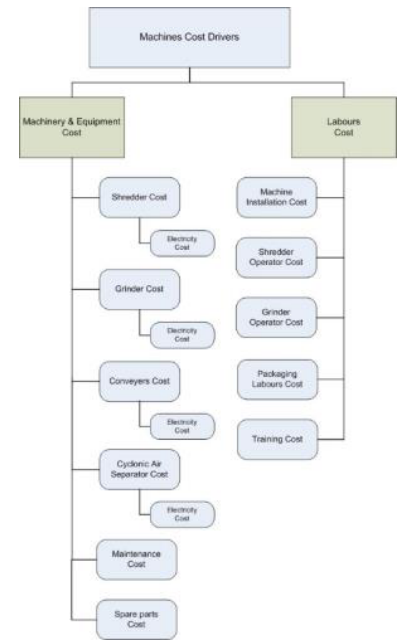

Figure 10. Machine cost drivers in mechanical recycling.

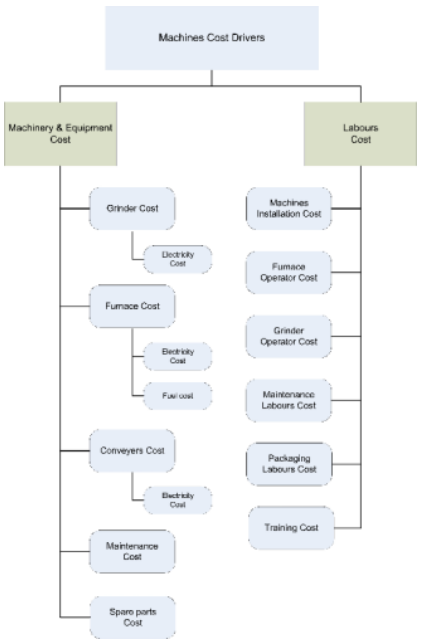

Figure 11. Machine cost drivers in thermal recycling. 


\section{Validation of Developed Framework}

The validation process is a critical procedure because it determines the accuracy of the developed framework. Moreover, the purpose of the validation process is to ensure that the gathered data from the literature review and the interviews are fully integrated with each other to shape the framework.

The validation procedure was analysed with experts in the field of $\mathrm{CFC}$ recycling and cost estimation. Face to face interviews were conducted with these experts which was more convenient than having a phone interview. Finally, after considering the expert comments, the modifications were added to the costing framework.

\section{Cost Estimation Tool Development}

The cost estimation tool is described as a presentation of the developed costing framework. Figure 12 shows the cost estimation tool structure. The tool represents the two recycling methods: mechanical recycling and thermal recycling. It provides an access to many options including the recycling process description, the work breakdown structure, the cost drivers and the cost estimation technique. This estimation tool might be utilised by many users or organisations involved in the composite area such as, composite recycling companies and environmental organisations.

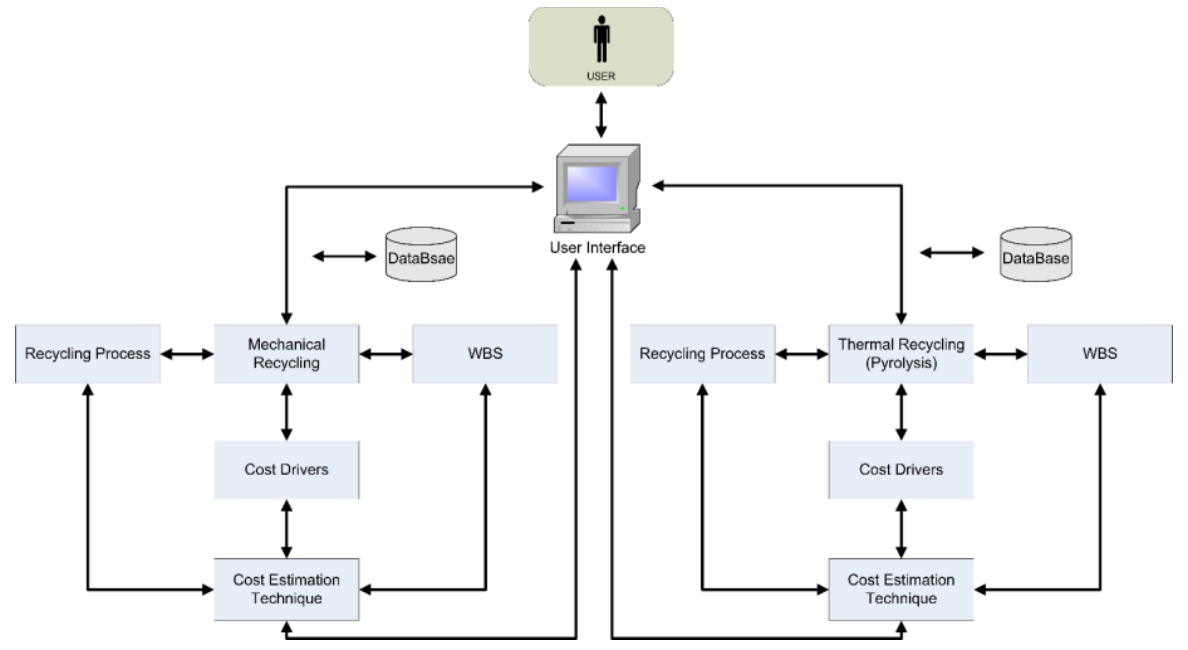

Figure 12. The cost estimation tool structure.

The flow diagram of the cost estimation technique is demonstrated in Figure 13. The main purpose of the cost estimation technique is to evaluate the economic drivers associated with the presented recycling process. The direct cost of the recycling process is divided into three costs: capital cost, operating cost and manpower cost. The input to this estimation tool includes the cost and number of machines, materials and manpower involved in the recycling process. This model is not considering the in-direct cost of the recycling process. The total cost is the summation of the three costs. 


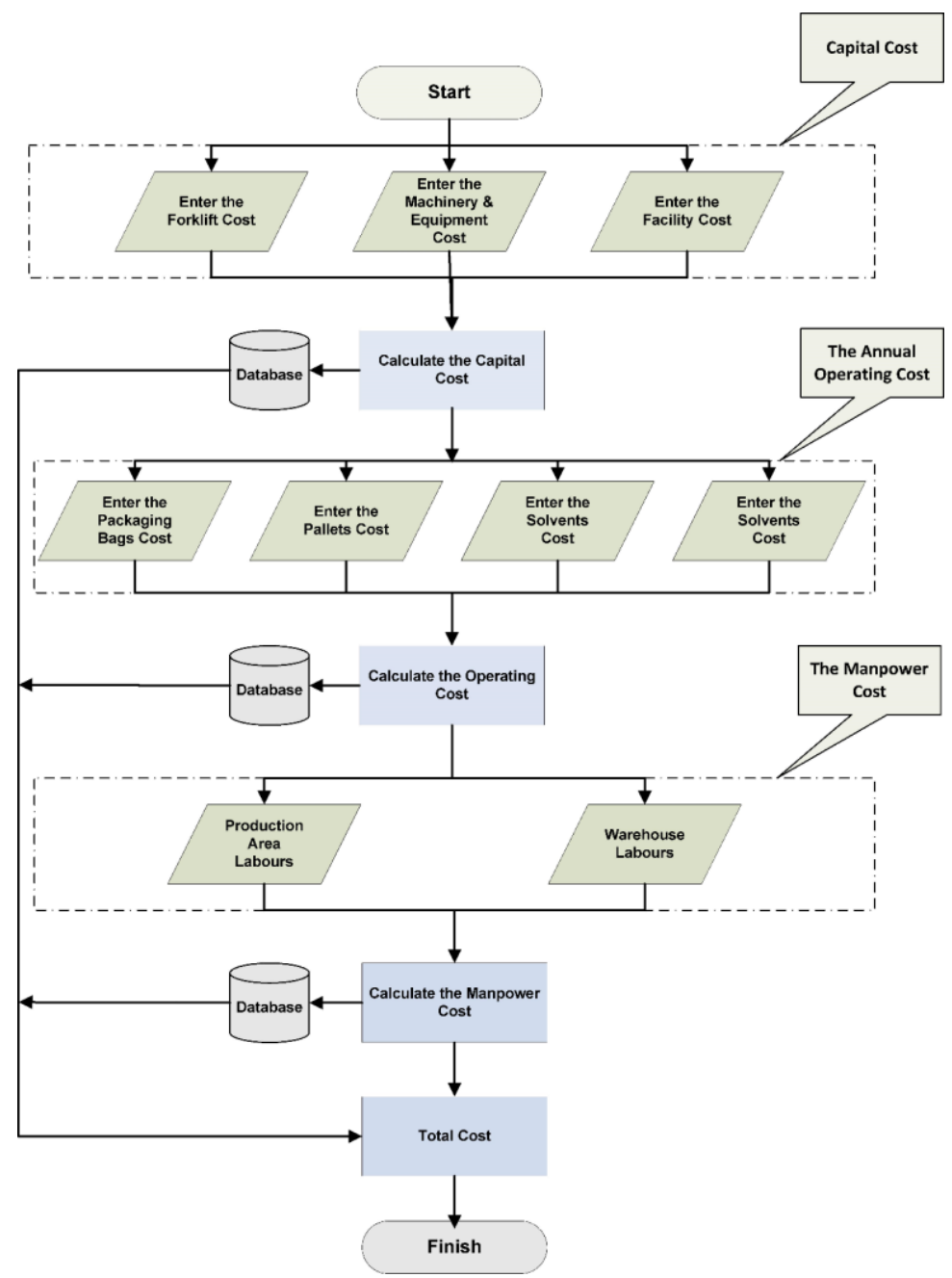

Figure 13. Scenario of the cost estimation of composites recycling.

\section{Conclusions}

The objectives stated at the beginning of the research project have been achieved throughout the development stages of the costing framework.

The framework, concentrating on CFC, was provided in terms of diagrams. The costing framework provides in depth understanding of:

- The two recycling process descriptions: mechanical recycling and thermal recycling.

- The work breakdown structure related to each process.

- The major cost drivers associated with the two recycling processes.

- The detailed cost drivers linked with each activity in the recycling process.

There are two kinds of CFC waste which can be recycled by using this framework; the manufacturing waste and the end of life scrap. Recycling facilities prefer to recycle 
manufacturing waste rather than end of life scrap because recycled CFC obtained by recycling the manufacturing waste has better quality.

Based on the work breakdown structure, the mechanical recycling is simpler than thermal recycling in terms of activities and machines. Still, the high cost of the recycling process is preventing the recycled CFC to compete with the virgin CFC.

The proposed costing framework can be used for different types of carbon fibre composites from different sectors. It offers opportunities to identify the activities where the cost is high, hence it can be improved.

A cost estimation tool was built to facilitate the developed costing framework. After entering the cost of each recycling method, a comparison can be made between the two recycling process by comparing the calculated total cost.

This research provides a costing framework for recycling carbon fibre composites (CFC). Potential future work might encompass three directions: the first direction is to collect quantitative data in order to build cost estimating relationship and more accurate costing model; the second direction is to include the third recycling process mentioned in the literature which is the chemical recycling process (the chemical recycling was not included in this framework because it is not commercialised yet); and the third direction might be to shift the focus from the CFC to glass fibre reinforced plastic 'GFRP'.

\section{References}

[1] E. Pisanova, Wiley Encyclopedia of Composites, John Wiley \& Sons, Hoboken, NJ, USA, 2012.

[2] T. Edwards, Composite materials revolutionise aerospace engineering, Ingenia, 2008, Vol. 36, pp. 2428.

[3] J. Davidson, 2006, Carbon fiber composite recycling: An industry perspective. Accessed: 10.04.2019. https://www.compositesworld.com/columns/carbon-fiber-composite-recycling-an-industry-perspective

[4] R. Price and J. Davidson, Recycling carbon fibre, Recycled Carbon Fibre Ltd, U.S. Patent 7922871, 2011.

[5] S. Mazumdar, Composites Manufacturing: Materials, Product, and Process Engineering, CRC Press, Boca Raton, Florida, 2001.

[6] A. Quilter, 2001, Composites in aerospace applications. Accessed: 10.04.2019. https://ihsmarkit.com/pdf/Composites-Aerospace-Applications-whitepaper_264558110913046532.pdf

[7] A.B. Strong, Fundamentals Of Composites Manufacturing: Materials, Methods and Applications, Society of Manufacturing Engineers, Michigan, USA, 2008.

[8] P. Grant, 2018, The aircraft at end of life sector: a preliminary study WingNet Report, Accessed: 16.06.2018. http://users.ox.ac.uk/ pgrant/WINGNet.html

[9] S. Halliwell, 2006, End of Life Options for Composite Waste: Best Practice Guide, Accessed: 23.07.2009. https://netcomposites.com

[10] S.J. Pickering, Recycling technologies for thermoset composite materials - current status, Composites Part A: Applied Science and Manufacturing, 2006, Vol. 37, pp. 1206-1215.

[11] P. Butterworth-Hayes, Europe pioneers aircraft recycling initiatives, Aerospace America, 2006, Vol. 44, pp. 4-5.

[12] D. Wilson, The implementation of recycled thermoset composites in thermoforming molds, Journal of Industrial Technology, 2003, Vol. 19, pp. 2-5.

[13] S.J. Pickering et al., A fluidised-bed process for the recovery of glass fibres from scrap thermoset composites. Composites Science and Technology, 2000, Vol. 60, pp. 509-523.

[14] H.L.H. Yip et al., Characterisation of carbon fibres recycled from scrap composites using fluidised bed process, Plastics, Rubber and Composites, 2002, Vol. 31, pp. 278-282. 